\title{
A formação do glide no alemão padrão
}

\section{Glide formation in Standard German}

\author{
Mágat Nágelo Junges \\ Universidade Federal de Santa Catarina, Florianópolis, Santa Catarina / Brasil \\ magat.nj@hotmail.com \\ Gean Nunes Damulakis \\ Universidade Federal do Rio de Janeiro, Rio de Janeiro, Rio de Janeiro / Brasil \\ damulakis@gmail.com
}

Resumo: Este artigo discute a formação do glide [j] na estrutura silábica do alemão padrão. Para isso, apresentam-se teorias fonológicas que dão conta da sílaba, desde a Fonologia linear, passando pela Não linear, e chegando a uma análise otimalista. Neste trabalho, leva-se em consideração o 'princípio da escala de sonoridade' (doravante, SSP) como possível parâmetro de compreensão para a análise do glide [j] em investigação, tal como a exigência de onset. Reanalisamos as possibilidades de ordenação do glide [j] na estrutura silábica interna do alemão padrão, de acordo com modelos teóricos recentes, sobretudo os não lineares, como as teorias autossegmental e métrica, e investigamos como isso poderia ser acomodado em um modelo fonológico que exclui (ou reduz) a derivação, como a teoria da otimalidade. Concluímos que na representação subjacente não é necessário especificar o status de glide [j], mas apenas de vogal alta, podendo uma hierarquia de restrições determinar sua posição na sílaba, sobretudo respeitante à sua nuclearidade.

Palavras-chave: glide [j]; estrutura silábica do alemão padrão; Teoria da Otimalidade (TO). 
Abstract: This paper discusses the glide [j] formation in the syllabic structure of Standard German (Hochdeutsch). For that, a discussion about phonological theories on the syllable was raised, from Linear Phonology and Non Linear Phonology to Optimality Theory (OT). In this paper, the Sonority Sequencing Principle (SSP) was taken into account as a possible parameter in order to comprehend the glide [j] under investigation, as well as the demand for onset position. Sequence possibilities of the glide [j] onto the internal syllabic structure of German were reanalyzed, according to recent theories, mainly the not linear ones as Autosegmental and Metrical. Furthermore, an investigation on the glide [j] formation in a phonological model that excludes (or reduces) the derivation - as the Optimality Theory - was carried out. Hence, the results have shown that it is not necessary to specify the glide [j] status in the underlying representation, but only that of high vowel. This way, a constraint hierarchy can determine its position in the syllable, especially its nuclearity.

Keywords: glide [j]; syllabic structure of Standard German (Hochdeutsch); Optimality Theory (OT).

Recebido em 9 de abril de 2017. Aprovado em 25 de agosto de 2017.

\section{Introdução}

Neste trabalho, investigamos a formação do glide [j] na sílaba do alemão padrão. A ideia de se trabalhar com o glide é motivada pelo fato de que esse segmento (de articulação dúbia entre vogais e consoantes) parece, ainda, não ser completamente bem definido na estrutura fonológica do alemão padrão (doravante, AP). Buscamos dar nova interpretação para uma adequação do glide na estrutura fonológica dessa língua, contrapondo exemplos de teorias fonológicas derivacionais e acomodando a análise nos pressupostos da TO, segundo a qual a divergência entre input e output se deve à avaliação de um conjunto de restrições hierarquizadas.

O AP conta com um inventário fonético de 17 sons vocálicos (se considerarmos a duração) e cerca de 30 sons consonantais (DAMULAKIS, 2008, p. 63-64). Desses sons, o único exemplo no alemão de aproximante é a palatal [j], como em: [j]a 'sim', [j]ugend 'juventude' (Ib., p. 64). 
Segundo Damulakis (2008), o segmento é visto como uma consoante, subjacentemente no AP.

O termo "glide" foi introduzido, pela primeira vez, por Sievers (1881), na sua teoria das três fases, sendo elas: on-glide, posição articulatória e off-glide. Sievers partiu da suposição de que os articuladores levam um tempo t mensurável na sua posição neutra ("de descanso") até se movimentarem fundamentalmente sobre o menor e menos audível glide para o próximo som. Essa teoria foi abandonada no início do século 20. Menzerath e Lacerda (1933, p. 58) estabelecem que a fala é um movimento de duração e que os articuladores, excepcionalmente, na maioria das vezes, permanecem por um tempo t determinado na mesma posição (apud MÜCKE, 1997, p. 02).

Tendo em vista essa descrição acústico-articulatória dos glides, interessa-nos, por outro lado, investigar a maneira como podem ser classificados na estrutura silábica do AP e a abordagem teórica fonológica que consegue dar conta, de maneira mais apropriada, do lugar dos glides, já que há glides pré- e pós-vocálicos no AP.

O modelo silábico proposto por Kahn (1976) compreende a sílaba como uma unidade, cujos segmentos encontram-se ligados diretamente ao nó silábico, enquanto o modelo silábico hierárquico, formulado por Selkirk (1982) e Harris (1983), considera-a em uma estrutura hierárquica interna. Optamos por considerar, neste trabalho, que a sílaba tem uma estrutura interna. Além disso, para darmos conta de nosso objetivo, lançaremos mão do "princípio da escala de sonoridade" (doravante, SSP) e seu papel importante, visto que os glides têm, em algumas propostas de escala, a mesma sonoridade que uma vogal.

Dividimos este artigo nas seguintes seções: seção 2, na qual a sílaba é apresentada como estrutura fonológica universal; seção 3, em que se apresentam as principais definições dos glides e indica-se, no item 3.1, a representação do glide [j] no alemão padrão baseada no modelo fonológico métrico de Selkirk (1982) e Harris (1983); seção 4, na qual se analisa o glide [j] na sílaba do alemão, e seção 5, que trata da formação do glide com base na Teoria da Otimalidade (OT).

\section{A sílaba como estrutura fonológica universal}

Sabemos que não há língua natural sem sílaba. O uso da sílaba para um falante nativo parece ser bastante intuitivo, e ela pode ser 
empregada em versos, rimas e canções, por exemplo. Algumas análises experimentais mostram, por exemplo, que a realidade cognitiva da sílaba é mais robusta que a de segmentos, uma vez que a alfabetização costuma aumentar a consciência de segmentos, ao passo que a sílaba pode ser considerada menos atrelada à alfabetização. Segundo Morais et al. (1979), embora não seja difícil levar analfabetos à consciência de segmentos, aqueles são tipicamente inconscientes da existência dessas unidades.

Do ponto de vista fonológico, a sílaba representa uma estrutura que ocorre em ambientes de regras fonológicas, tanto para derivar alofones quanto em alternância morfofonêmica. As sílabas também são consideradas unidades que contêm o acento tônico e que servem de base para tons em sistemas tonais, bem como para a entonação ${ }^{1}$ (HAYES, 2009, p. 250).

Para Carr (1993, p. 195 apud BROCKHAUS, 1999, p. 170), a estrutura silábica é considerada indispensável para se expressar muitas generalizações fonológicas. Com base nessa constatação, Kenstowicz (1994, p. 250) enumera três argumentos ${ }^{2}$ para a sílaba como um conceito útil em fonologia (tradução nossa):

a) (A sílaba) é um domínio natural para a explanação de muitas restrições fonotáticas.

b) Regras fonológicas são frequentemente expressas de maneira mais simples e mais razoável se elas se referirem, explicitamente, à sílaba.

c) Vários processos fonológicos são mais bem interpretados como métodos para assegurar que a cadeia de segmentos fonológicos seja dividida em sílabas.

\footnotetext{
1 "Looking within Phonology itself, we find that syllables frequently appear in environments of phonological rules, both for deriving allophones and in morphophonemic alternation. Syllables also are the units that bear stress and serve as the 'anchor points' for tones in tonal systems and in intonation. It is hardly surprising that phonologists have often made use of syllables in phonological theory." (HAYES, 2009, p. 250)

${ }^{2}$ The main arguments which have led to this position are conveniently summarized in Kenstowicz (1994, p. 250) and can be stated as in (1).

(1) The syllable is a useful concept in phonology, for three main reasons:

a. It is a natural domain for the statement of many phonotactic constraints;

b. Phonological rules are often more simply and insightfully expressed if they explicitly refer to the syllable.

c. Several phonological processes are best interpreted as methodes to ensure that the string of phonological segments is parsable into syllables.
} 
Outras compreensões acerca do assunto tomam a sílaba como uma "unidade bem reconhecida na análise linguística, que explica muito bem o número de unidades rítmicas que serão perceptíveis numa palavra ou numa elocução longa. Esse número é geralmente igual ao número de vogais da elocução.”’3 (MADDIESON, 2001, p. 1). Também se pode dizer que a sílaba é uma unidade fonológica que organiza as melodias segmentais em termos de sonoridade (BLEVINS, 1995). De acordo com as definições acerca da sílaba, depreende-se que ela tem um papel fundamental para a estrutura prosódica de toda língua natural. No entanto, como podemos representá-la?

Como bem lembra Collischonn (2001,p. 91-92), há basicamente duas teorias a respeito da estrutura interna da sílaba: a teoria autossegmental e a teoria métrica da sílaba. De acordo com a primeira, pressupõem-se camadas independentes na estrutura silábica. Segundo Cristófaro Silva (2011, p. 111-117), essa proposta teórica tem o objetivo de integrar vários níveis da descrição do componente fonológico. É representada, abaixo, em (a). Já a Fonologia Métrica se dedica a analisar fenômenos suprassegmentais, especialmente a respeito da atribuição do acento no nível da palavra. Essa teoria defende que as sílabas são estruturadas como representado em (b), conforme Selkirk (1982), baseando-se em propostas feitas anteriormente por Pike e Pike (1974) e Fudge (1969). as teorias:

A Figura 1, a seguir, mostra as representações silábicas em ambas

FIGURA 1 - Representações da sílaba

(a)

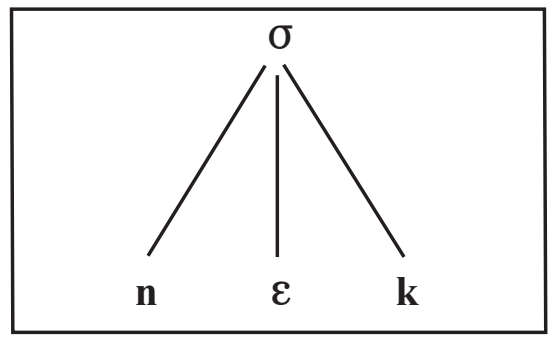

Fonte: Colischonn, 2001, p. 91. (b)

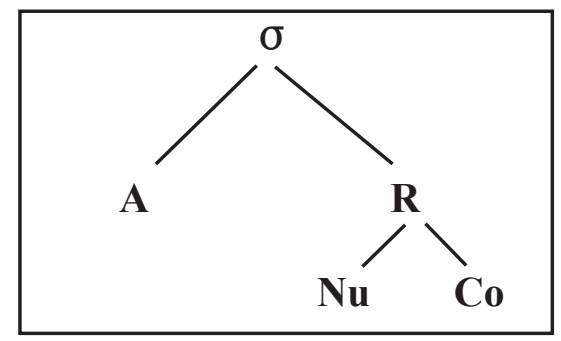

3 “The syllable is a well-recognized unit in linguistic analysis which explains quite well the number of rhythmic units that will be perceived in a word or longer utterance. This number is usually equal to the number of vowels in the utterance." (Chapter Syllable Strucutre: http://wals.info/chapter/12) 
A constituição da sílaba tônica [nck] da palavra "connective" do inglês é exibida, acima, em 1(a), Figura 1, na estrutura arbórea, indicada em Hayes (2009). Como podemos observar, a letra grega sigma $\sigma$ é empregada para a representação da sílaba. Por outro lado, na representação presente em Collischonn (2001) - reproduzida em 1b, podemos observar a divisão hierárquica na estrutura silábica em ataque (A) ou onset (posição ocupada por consoantes) e rima (R) (dividida em núcleo $(\mathrm{Nu})$ e coda $(\mathrm{Co}))$.

De acordo com Maddieson (2015, p. 2), os "modelos silábicos canônicos são, na maioria das vezes, representados por um feixe de consoantes $(\mathrm{C})$ e vogais $(\mathrm{V})[\ldots]$ ". . A sílaba canônica, que se considera a sílaba leve e simples e que está presente potencialmente em todas as línguas naturais é a sílaba $\mathrm{CV}^{4}$ (core syllable), que, em termos otimalistas, equivale ao padrão silábico não marcado. Por exemplo, línguas como o havaiano (Havaí) e o Adamawa-Ubangiã (República Democrática do Congo) só têm esse tipo de sílaba. Em Maori (Nova Zelândia), por sua vez, há sílabas $C V$, além de V somente. Se a sequência silábica CV for acrescida de consoantes, obtêm-se sílabas mais elaboradas do tipo CVC e CCV. Além dessas possibilidades, há também sistemas silábicos complexos moderados, nos quais se permite somente uma única $\mathrm{C}$ depois da vogal ou duas $\mathrm{C}$ antes dela. Um exemplo de língua como essa é o Darai, falado na região indo-ariana e no Nepal, na qual uma amostra dessa estrutura seria o vocábulo /bwak/ (CCVC) "seu pai". Outra ocorrência de tipo silábico nas línguas naturais se dá no inglês, em que sequências de sistemas silábicos complexos são permitidos. Por exemplo, no vocábulo [strenk $\theta \mathrm{s}$ ] (CCCVCCCC) strengths (Ib., p. 2-3). De maneira geral, quando uma língua permite complexidade (CCV[C] ou [C]VCC) e não canonicidade silábicas (V[C]), ela também tolera simplicidade (CV[C]) e canonicidade (CV). O oposto não é verdadeiro. Dito de outra forma: a) a presença de codas é universalmente marcada, e a falta de onset também o é; b) esses constituintes tendem a ser simples, universalmente (KAGER, 1999).

Em se tratando da complexidade silábica, conceito importante é o de sequência de sonoridade, considerada uma das condições universais para a formação da sílaba. O que ocorre, de fato, é que o elemento mais sonoro irá sempre ocupar a posição de núcleo, e os elementos menos

\footnotetext{
${ }^{4} \mathrm{CV}$ ( $C V$ syllable), sílaba constituída por consoante e vogal. É tida como sílaba universal, pois é a única que ocorre em todas as línguas naturais. (Ib., p. 85)
} 
sonoros ocuparão ataque e coda. O SSP (Sonority Sequencing Principle - Princípio de sequência de sonoridade), baseado em Sievers (1881) e Jespersen (1904), advoga que há uma "escala de sonoridade" para a sílaba, que cresce do seu início até o seu pico e decresce do pico até a coda. Esse princípio opera por meio das línguas naturais, com algumas exceções. Segundo Clements (1990, p. 19),

as sílabas são normalmente caracterizadas por um aumento e uma diminuição na sonoridade, que se refletem nos valores da escala de sonoridade, caracterizando cada um de seus segmentos. As sequências de sílabas exibem um aumento e uma diminuição quase periódicos em sonoridade, cada um repetindo uma porção a qual pode ser chamada de ciclo de sonoridade. É possível ajustar uma curva ou delineá-la sobre tais representações que refletem esse aumento e essa diminuição, como apresentado na Figura 2 , consistindo de dois ciclos: ${ }^{5}$

FIGURA 2 - Escala de sonoridade (vocábulo 'template', do inglês), de acordo com os traços soante, aproximante, vocoide e silábico

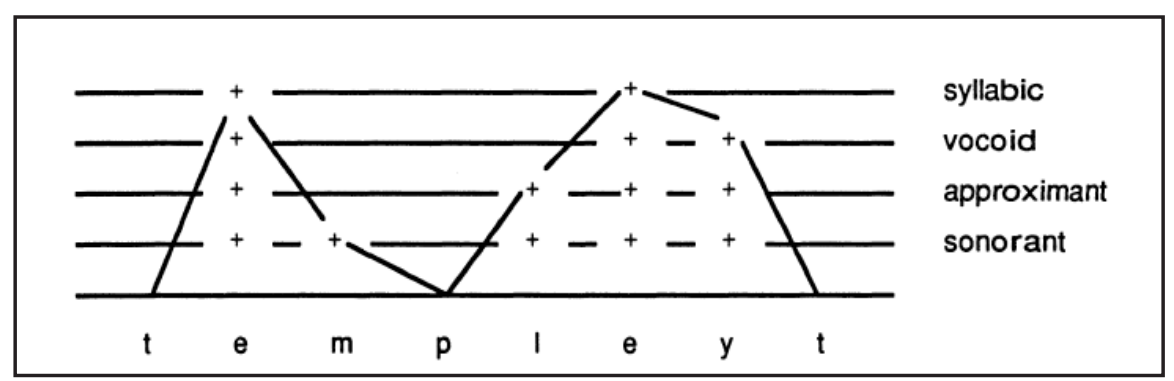

Fonte: Clements, 1990, p. 20: Ilustração 12.

Segundo o autor (1990, p. 20), o número de ciclos, cujo pico decresce da linha do topo ([silábico]) deste diagrama, corresponderá

5 " [...] syllables are normally characterized by a rise and fall in sonority which is reflected in the sonority scale values characterizing each of their segments. Sequences of syllables display a quasiperiodic rise and fall in sonority, each repeating portion of which may be termed a sonority cycle. It is possible to fit a curve or outline such representations which reflects this rise and fall, as shown in (12), consisting of two cycles." (CLEMENTS, 1990, p. 19) 
exatamente ao número de sílabas, exceto o de um patamar ao longo da linha do topo (representando uma sequência de vogais) que pode ser analisada como uma sequência de picos silábicos. ${ }^{6}$ Observamos, assim, alguns vocábulos do alemão padrão, cuja segunda vogal é omitida do núcleo silábico, quando produzida (representada pelo diacrítico 。:

Exemplos:

können [køn-no 'poder/ser apto a';

wollen [vol-no] 'querer' vs. Köln [køln] 'Colônia' (cidade).

Clements (1990, p. 20) propõe, então, o "Princípio da Silabificação do Núcleo" (The Core Syllabification Principle, CSP), partindo do exemplo 'template' apresentado. Baseado em Kahn (1976), o autor afirma que, para o traço [+silábico], os segmentos são definidos por uma língua natural em questão, e introduz um nó silábico sobre esse traço. Esse passo pressupõe que os elementos silábicos já constam da representação, a esse ponto, se criados por uma regra ou por subjacência (no caso de línguas que têm distinções imprevisíveis entre glides e vogais ou outros segmentos que se diferenciam somente em silabicidade, como o francês, por exemplo).

Esse princípio é apresentado por Clements (1990, p. 20-21) da seguinte maneira:

Princípio da Silabificação do Núcleo ${ }^{7}$ (CSP):

a. Associa-se cada segmento [+silábico] a um nó silábico.

\footnotetext{
6 "The number of cycles whose peaks fall on the top ([syllabic]) line of this diagram will correspond exactly to the number of syllables, except that a plateau along the top line (representing a sequence of vowels) may be persed as a sequence of syllable peaks." (CLEMENTS, 1990, p. 20)

7 (13) The Core Syllabification Principle (CSP):

a. Associate each [+syllabic] segment to a syllable node.

b. Given P (an unsyllabified segment) preceding Q (a syllabified segment), adjoin $\mathrm{P}$ to the syllable containing $\mathrm{Q}$ iff $\mathrm{P}$ has a lower sonority rank than $\mathrm{Q}$. (iterative)

c. Given Q (a syllabified segment) followed by R (an unsyllabified segment), adjoin $\mathrm{R}$ to the syllable containing $\mathrm{Q}$ iff $\mathrm{R}$ has a lower sonority rank than $\mathrm{Q}$. (iterative)

CLEMENTS (1990, p. 20-21)
} 
b. Dado P (um segmento não silabificado) precedendo Q (um segmento silabificado), junta-se $\mathrm{P}$ à sílaba contendo $\mathrm{Q}$, se $\mathrm{P}$ tem uma classificação sonora mais baixa a Q. (iterativo)

c. Dado Q (um segmento silabificado) seguido de R (um elemento não silabificado), junta-se $\mathrm{R}$ à sílaba contendo $\mathrm{Q}$, se $\mathrm{R}$ tem uma classificação sonora mais baixa a Q. (iterativo)

Wiese (1998, p. 91 apud RAMERS, 1998, p. 94), por sua vez, sugere para o AP, conforme mostrado na Figura 3, a seguinte escala de sonoridade da sílaba para a fonotática dessa língua:

FIGURA 3 - Escala de sonoridade para a sílaba no alemão com aumento de sonoridade da esquerda à direita

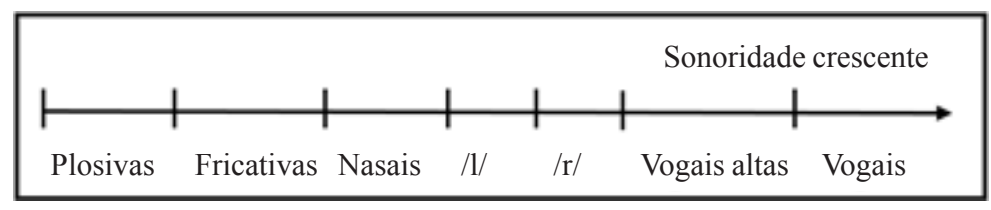

Fonte: Ramers, 1998, p. 94: Ilustração 4-34, tradução nossa.

Uma escala desse tipo tem traços universais, entretanto está relacionada à sua forma detalhada e específica a uma língua em particular (note-se, por exemplo, que, na escala da Figura 3, as vogais altas estão separadas das demais vogais; isso é importante para o que defendemos aqui). A correlação entre a escala de sonoridade e a fonotática é apresentada por Selkirk (1984a, p. 116 apud RAMERS, p. 94) por meio da 'generalização da sequência de sonoridade' (Sonority Sequencing Generalization): "Em qualquer sílaba, há um segmento constituindo um pico de sonoridade que é precedido e/ou seguido por uma sequência de segmentos com valores de sonoridade progressivamente decrescentes". ${ }^{8}$

\footnotetext{
8 "In any syllable, there is a segment constituting a sonority peak that is preceded and/ or followed by a sequence of segments with progressively decreasing sonority values." (SELKIRK, 1984a, p. 116)
} 


\section{Os glides}

A questão do $u$ consoante e do $u$ vogal, do $i$ consoante e do $i$ vogal é absolutamente dependente da questão da sílaba. Quem professa uma opinião determinada sobre $u$ consoante e u vogal, sem ter visão perfeitamente clara e precisa sobre a sílaba, fala ao acaso. (SAUSSURE, 2002 [1916], p. 209)

Observamos, com base no que afirma Ferdinand de Saussure, no que se refere ao i-j, u-w e à teoria natural da sílaba, que os glides já eram tema de discussão para a análise linguística que foi trilhada pelo autor, a saber: a denominação empregada por ele classifica-os como "i consoante/i vogal" e "u consoante/u vogal". Para nós, o "i consoante e u consoante" dizem respeito, a priori, aos glides ou semivogais, ou, também, denominados pelo autor (2006, p. 71-72) de fonema de abertura 4 , ao ponto que "i vogal e u vogal" dizem respeito às vogais, naturalmente, ou soantes, como Saussure mesmo as denomina.

Antes de apresentar o glide no sistema silábico do alemão, com base na fonologia métrica, que também será apresentada, é necessário definir as compreensões que se tem desse tipo de segmento.

Uma definição para glide $e^{9}$ pode ser observada em Cristófaro Silva (2011), segundo a qual se compreende o termo como

segmento que apresenta características articulatórias de uma vogal, mas que não pode ocupar a posição de núcleo de uma sílaba. Diz-se que o glide é uma vogal assilábica, ou seja, uma vogal que não pode ser o núcleo de uma sílaba. Portanto, um glide não pode receber acento. É indicado com o símbolo de uma vogal acrescido do

\footnotetext{
${ }^{9}$ Por meio dessa definição, alguns exemplos de vocábulos do português brasileiro (doravante, PB) são apresentados, a seguir, pela autora: em ditongos centralizados: o glide pode ser um schwa como, na palavra bola, pronunciada como b[oə] ]la. Glides sempre ocorrem precedendo - nac[Io]nal - ou seguindo - c[au ] sa - uma vogal. Quando são seguidos de uma vogal, formam um ditongo crescente: nac[Io]nal. Quando são precedidos de uma vogal, formam um ditongo decrescente: $\mathrm{c}[\mathrm{au}] \mathrm{s}$ sa. Geralmente, os glides se manifestam com características articulatórias de vogais altas anteriores ou posteriores. Outras denominações para glide são semivogal e semiconsoante (CRISTÓFARO SILVA, 2011, p. 127).
} 
diacrítico []. Tipicamente, os glides ocorrem nas línguas naturais como vogais altas assilábicas. (CRISTÓFARO SILVA, 2011, p. 127) se afirmar que

Do ponto de vista acústico-articulatório acerca dos glides, podeum tipo de som que apresenta propriedades de ambas consoantes e vogais é denominado glide. Os glides podem ser pensados como vogais ligeiramente articuladas, devido à impressão auditiva que eles produzem. Os glides são pronunciados com uma articulação de uma vogal. Entretanto, eles se movimentam rapidamente para outra posição articulatória, como acontece nos glides iniciais em yet ou wet, ou que rapidamente acabam no fim de vocábulos como em boy e now , no inglês. ${ }^{10}$ (DOBROVOLSKI; KATAMBA, 1990, p. 23)

Na compreensão de Clements e Hume (1995), os glides [j] e [w] e as vogais altas [i] e [u] não são distinguíveis por traços, sendo suas diferenças apenas contextualmente definidas: diferem entre si pelo fato de as vogais altas poderem ser núcleos de sílaba, ao passo que os glides apenas podem ocupar as margens da sílaba. Dessa forma, esses elementos compartilham igualmente dos valores de traços de raiz no sistema proposto pelos autores: [+soante], [+aproximante] e [+vocoide]. Há propostas alternativas na Geometria dos Traços. Como veremos mais adiante, seguimos, por exemplo, Padget (2008), que defende que haja distinção entre $[i, u]$ e $[j, w]$ no que se refere ao traço [vocálico]: os dois primeiros são valorados positivamente quanto a esse traço, ao passo que $[\mathrm{j}, \mathrm{w}]$, negativamente.

Mesmo tendo articulação de vogais, os glides não se comportam, na estrutura silábica, prototipicamente como estas. Eles apresentam propriedades de consoantes e de vogais, por isso os termos semiconsoante

10 "A type of sound that shows properties of both consonants and vowels is called a glide. Glides may be thought of as rapidly articulated vowels - that is the auditory impression they produce. Glides are produced with an articulation like that of a vowel. However, they move quickly to another articulation, as do the initial glides in yet or wet, or quickly terminate, as do the word-final glides in boy and now." (DOBROVOLSKI; KATAMBA, 1990, p. 23) 
e semivogal podem ser empregados intercambiavelmente com o termo glide. A sequência de vogal e glide costuma resultar no que chamamos tradicionalmente de ditongos. De acordo com Seara, Nunes e LazzarottoVolcão (2011), observa-se, sobretudo, que

os ditongos constituem-se de dois segmentos vocálicos. Há, no entanto, duas possibilidades de sequência em uma mesma sílaba: vogal semivogal ou semivogal vogal. As sequências finalizadas por semivogal são sempre inseparáveis e são chamadas de ditongos decrescentes, pois terminam pela vogal com menor proeminência acentual [ou seja, a semivogal]. Na sequência, semivogal e vogal, chamada de ditongo crescente, já que é finalizada pelo segmento de maior proeminência (a vogal), há a possibilidade de esses dois segmentos constituírem sílabas separadas. (SEARA; NUNES; LAZZAROTO-VOLCÃO, 2011, p. 42)

Essa definição de ditongos está ancorada na estrutura silábica do português brasileiro e trata o glide como um elemento vocálico. $\mathrm{O}$ ditongo pode ser, grosso modo, analisado como um deslizamento de um alvo articulatório para o outro, tratando-se de vogal e semivogal e/ou semivogal e vogal. É dessa maneira que Clark e Yallop (1995), abordam os ditongos, que, segundo os autores,

são definidos como movimentos articulatórios, particularmente da língua, que ocupam uma porção substancial de um ditongo, e que podem ser definidos em termos de dois alvos vocálicos que determinam a extensão e a direção do glide entre eles. Os ditongos podem ser mapeados no diagrama das vogais cardinais, e são transcritos por um diagrama composto de um símbolo com duas vogais que melhor representam os dois alvos. ${ }^{11}$ (CLARK; YALLOP, 1995, p. 35)

\footnotetext{
11 “[...] Articulatory movement, particularly of the tongue, occupies a substantial portion of a diphthong, which can be defined in terms of two vocalic targets that determine the range and direction of the glide between them. Diphthongs may be mapped on a cardinal vowel diagram, and are transcribed by a digraph consisting of the two vowel symbols which best represent the two targets." (CLARK; YALLOP, 1995, p. 35)
} 
A representação dos glides proposta pelos autores é mostrada na Figura 4 a seguir.

FIGURA 4 - Exemplos de vogais onglide e offglide

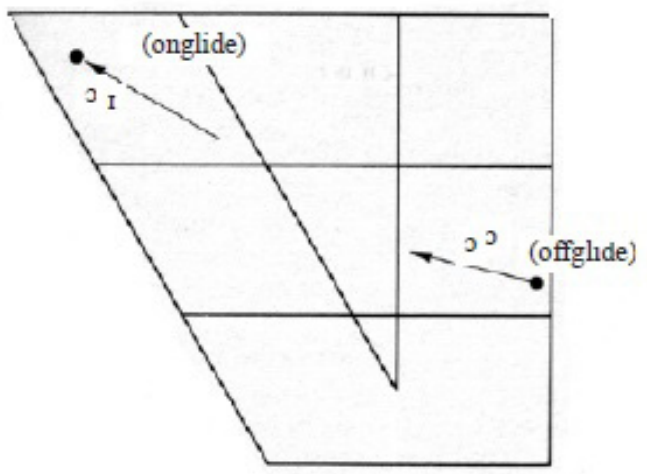

Fonte: Clark; Yallop, 1995, p. 35.

Em uma abordagem acústica, observamos, no trabalho de D.Kent e Read (2015), a seguinte consideração sobre ditongos:

Os ditongos são uma outra classe de sons relacionados a vogais. Os ditongos são como vogais pelo fato de serem produzidos com um trato vocal relativamente aberto e uma estrutura formântica bem definida e de servirem como núcleo de uma sílaba. Os ditongos são diferentes das vogais, pois eles não podem ser caracterizados por um formato único de trato vocal ou um padrão formântico único. Os ditongos são sons dinâmicos, em que o formato articulatório (e, portanto, o padrão formântico) muda vagarosamente durante a produção do som. (D.KENT; READ, 2015, p. 226)

Na Figura 5, a seguir, são exibidos os valores formânticos para os ditongos /aI/, /oI/ e /av/. De acordo com D.Kent e Read (2015, p. 227), "Cada ditongo pode ser representado nos eixos F1-F2 por uma trajetória que começa com as frequências dos formantes do onglide e termina com as frequências dos formantes do offglide" (as pontas das flechas indicam a direção da mudança de frequência). O gráfico abaixo, diferentemente do que é rotineiro à visualização acústica, apresenta F1 no eixo horizontal e F2 no eixo vertical: 
FIGURA 5 (figura 4.16, original) - Trajetórias F1-F2 para os três ditongos /aI/, /oI/, /av/

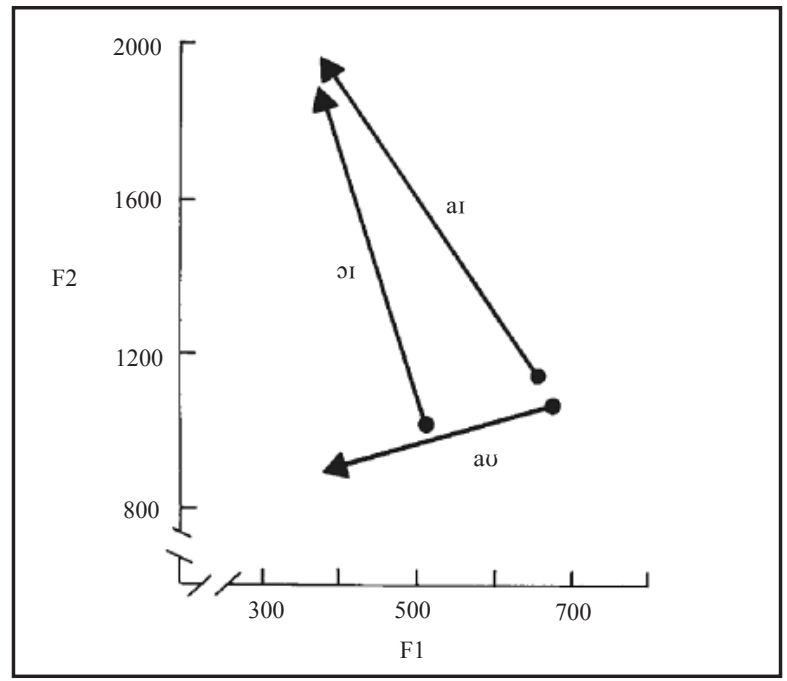

Fonte: D. Kent e Read, 2015, p. 227.

Uma vez definido o glide, parte-se, portanto, para a sua inserção na estrutura silábica do alemão, proposta pelo modelo da fonologia não linear.

\subsection{Representação do glide [j] no alemão padrão baseada no modelo de Selkirk (1982) e Harris (1983)}

Como apresentamos na Introdução, a sílaba pode ser representada por dois modelos fonológicos: o autossegmental e/ou o métrico. O segundo tem a vantagem de dar conta da divisão silábica da estrutura interna perante o tipo de segmento em questão (os glides, ou semivogais, ou semiconsoantes), como mostraremos a seguir. ${ }^{12} \mathrm{~A}$ representação do glide na divisão interna da estrutura da sílaba faz-nos assumir a posição de que os elementos têm certo tipo de relação entre si. Segundo Cristófaro Silva (2011, p. 117), o modelo métrico é "toda proposta teórica que assume que a organização fonológica se dá em camadas hierarquicamente

\footnotetext{
${ }^{12}$ Referimo-nos à representação em " $\mathrm{x}$ " em vez de CV, pois os glides podem apresentar comportamento tanto de vogal quanto de consoante (articulatoriamente são vogais, fonologicamente são consoantes). (MATEUS ; D’ANDRADE, 2000, p. 54).
} 
ordenadas e que a sílaba é uma importante unidade na representação fonológica".

A estrutura da sílaba do alemão pode ser exemplificada, na Figura 6, pela divisão silábica do vocábulo krank 'doente', em alemão, proposta por Ramers (1998):

FIGURA 6 - Estrutura do vocábulo monossilábico krank, de acordo com o modelo de constituintes

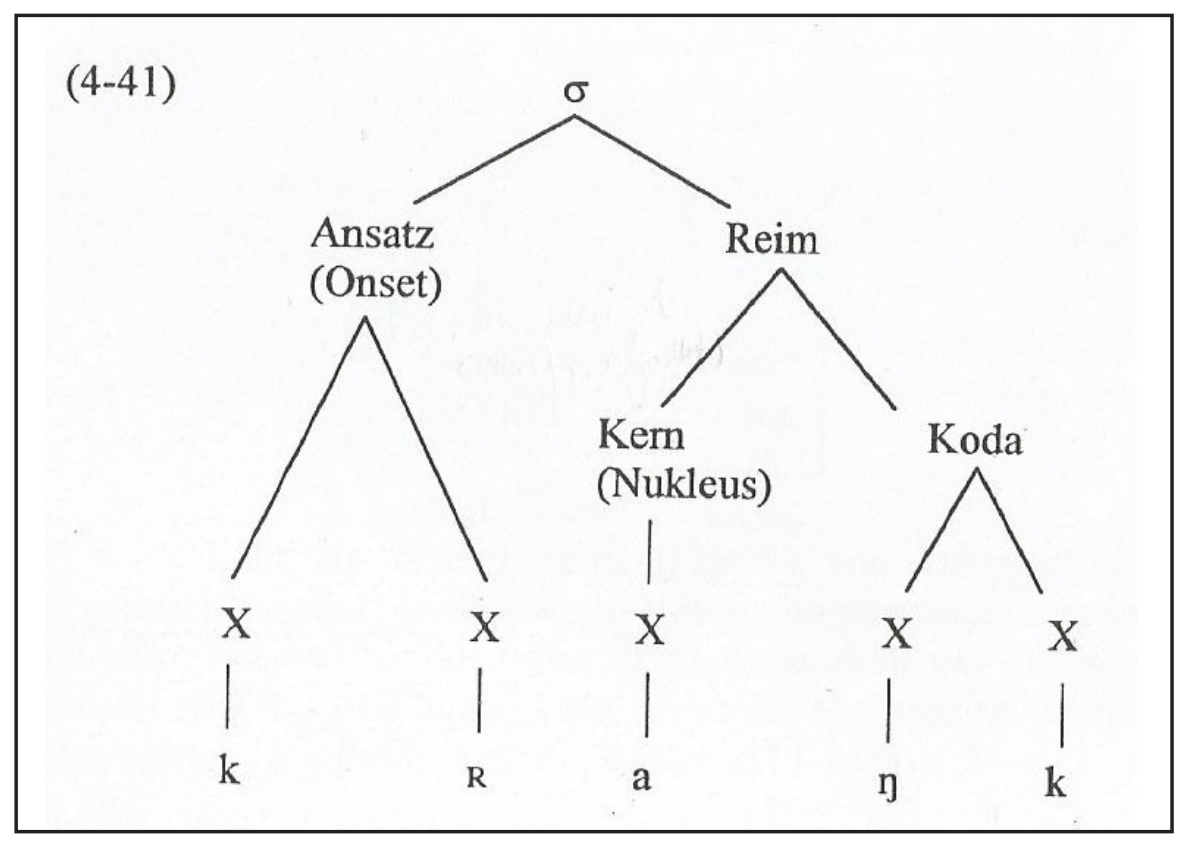

Fonte: Ramers, 1998, p. 98-99; Imagem 4-41.

Nessa representação esqueletal do alemão, verificamos a divisão interna da sílaba em Ansatz/Onset e Reim/Rima, que, por sua vez, dividese em núcleo (Kern/Nukleus) e coda (Koda). O ataque (ou onset) da sílaba, que possui dois constituintes $/ \mathrm{k} / \mathrm{e} / \mathrm{R} /$, é, portanto, ramificado, bem como a coda em $/ \mathrm{y} /$ e $/ \mathrm{k} /$, permanecendo o núcleo com a vogal baixa $/ \mathrm{a} /$.

Delattre (1964, p. 94), por sua vez, ao comparar as vogais do inglês, alemão, francês e espanhol, em sua obra, chama a atenção para um fator fundamental: o primeiro concerne à diferença entre ditongo $\mathrm{x}$ ditongação (por exemplo, quando o inglês ditonga seus monossílabos), ou seja, segundo o autor, o alemão (e o espanhol) têm ditongos, mas não 
ditongam perceptualmente seus vocábulos monossílabos (como o inglês americano o faz), com exceção da variante bávara do vocábulo gut [ḡuat], cuja realização é de ditongo. (BRENNER; HUSKZA; MARINKÁS, 2006, p. 69)

Ainda com relação à estrutura dos ditongos, Brenner, Huszka e Marinkás (2006) frisam que o ponto de partida dos movimentos articulatórios não deve coincidir automaticamente com o ponto de partida do primeiro elemento do ditongo, bem como a extremidade (também) não deve coincidir com a extremidade do segundo elemento do ditongo. Segue avante a explanação dos mesmos autores:

De acordo com o movimento da língua na cavidade oral distinguem-se, em geral, dois tipos de ditongos: 1. Fechado (ou crescente) e 2. Aberto (ou decrescente). Na variedade da língua alemã padrão, só existem ditongos crescentes (ou fechados). (BRENNER; HUSZKA; MARINKÁS, 2006, p. 69)

Cabem, ainda, alguns esclarecimentos a respeito da classificação em "ditongo crescente/decrescente" (steigend/fallend, em alemão), dependente da posição do glide na sílaba do alemão. Basendo-nos em critérios fonológicos, essa divisão na classificação dos ditongos referese a um parâmetro acústico-auditivo pelo qual se percebe o glide, isto é, se o glide ocupar a posição pós-vocálica no núcleo silábico, ele será considerado assilábico (unsilbisch, em alemão). Por essa razão são considerados ditongos decrescentes.

A seguir, são arrolados os três ditongos existentes no alemão, segundo os autores Brenner, Huszka e Marinkás (2006, p. 70-71), mantidas as representações originais:

[au]: representado pelo grafema $<\mathrm{au}>$, como no vocábulo auf 'preposição', esse ditongo ocorre no início, meio e fim da palavra e, na maioria das vezes, em posição tônica. O ditongo $[\widehat{\mathrm{a} U}]$ compõe-se de diversos elementos do [a] e do [u], isto é, de movimentos de deslizes (glides) associados juntamente à articulação. $\mathrm{O}$ primeiro componente do ditongo não é arredondado, já o seu segundo componente é arredondado.

[ar]: representado pelos grafemas $<\mathrm{ei}>,<\mathrm{ai}>,<\mathrm{ey}>\mathrm{e}<$ ay $>$, como nos vocábulos eins 'um, uma', Mai 'maio', Meyer 
'sobrenome' e Bayer 'bávaro', que sempre ocorrem nas posições iniciais, médias e finais, em sílaba tônica. O ditongo [ä] compõe-se de diversos elementos do [a] e do [I], isto é, da passagem fluída junto à articulação.

[эI]: representado pelos grafemas $<$ eu $>,<$ äu $>,<$ oi $>$ e $<$ oy $>$, como nos vocábulos Äußerung 'expressão' e Eule 'coruja', que sempre ocorrem nas posições iniciais, médias e finais.

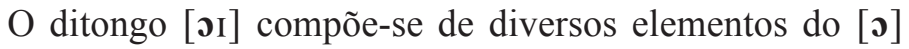
e do [I], isto é, da passagem fluída junto à articulação. O primeiro componente do ditongo é arredondado, já o segundo componente, não.

Esses ditongos são apresentados, a seguir, por Delattre (1964), na Figura 7, e por Ramers (1998), na Figura 8, respectivamente:

FIGURA 7 - Os principais ditongos do alemão em relação à sua configuração acústica

1

$\mathbf{u}$

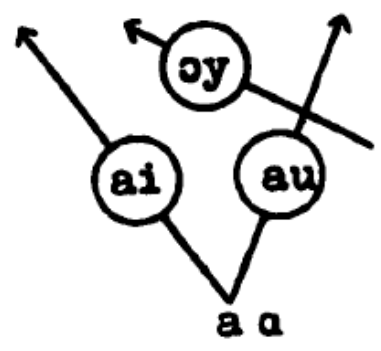

German

Fonte: Delatre, 1964, p. 81; German. 
FIGURA 8 - Os ditongos no alemão padrão

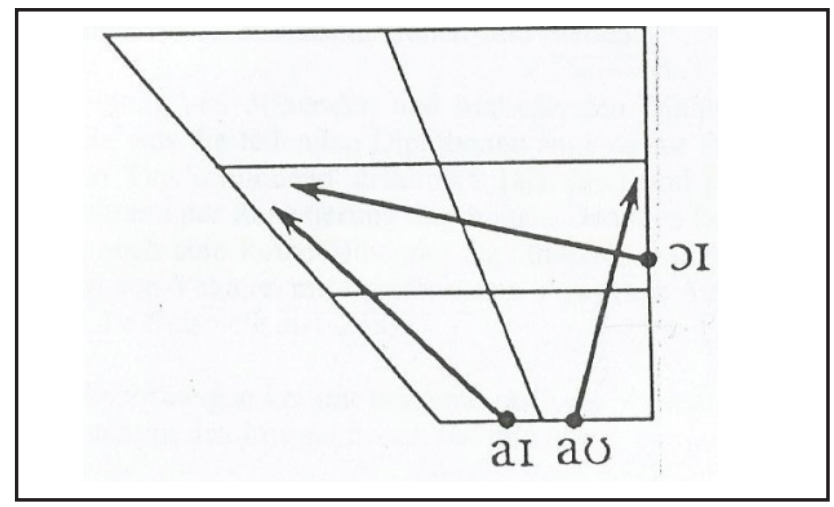

Fonte: Ramers, 1998, p. 36; Abbildung 7.

Nessas duas imagens, podemos visualizar que, nos ditongos [aI] e [or], há movimento em direção à posição com alvo acústico-articulatório da vogal alta anterior não-arredondada (distendida) [I]. Já no ditongo [au], há movimento para a posição posterior do trapézio vocálico, alcançando o alvo acústico-articulatório da vogal alta posterior [U].

Em vocábulos como "Spanien [Espanha], Linie [linha], Studium [curso superior] e Grobian [grosseiro]" (RAMERS, 1998, p. 37), é recorrente a realização com glide [j] + vogal silábica, dependendo principalmente da velocidade de fala. Junto a essa realização, também observamos a realização da variante silábica [I] + vogal silábica - a distribuição das vogais em duas sílabas separadas, formando, portanto, um hiato, que costuma ser evitada em muitas línguas. Analogamente, os exemplos apresentados pelo autor, "manuell [manual], Linguistik [Linguística], Ritual [ritual], Kloake [cloaca]”, com a realização 'glide [w] + vogal silábica' co-ocorre com a variante 'vogal silábica + vogal silábica'. Essa variação parece sugerir que subjacentemente se trata de vogais altas, que podem oscilar com realizações de glides, sobretudo em fala rápida.

Podemos concluir, brevemente, que os glides no AP parecem ocorrer categoricamente como tal apenas em posição de ditongo decrescente, isto é, são recorrentes nessa posição. O fato de não poder haver alongamento vocálico em um contexto como esse parece indicar que esse elemento faz parte do núcleo silábico. Voltaremos a essa questão mais adiante. Vejamos, na próxima subseção, como podemos analisá-los na estrutura silábica do alemão. 


\section{Análise do glide [j] na estrutura silábica do alemão padrão}

$\mathrm{Na}$ Seção 1, apresentamos a representação da sílaba nas línguas naturais. Nela, a posição central da Rima $(\mathrm{R})$ é o núcleo $(\mathrm{N})$, que é governado pela primeira. Para podermos tratar dos glides na estrutura silábica do alemão, devemos, primeiramente, compreender como o núcleo da sílaba funciona nessa língua.

Assim, devemos nos atentar para o fato de que existem algumas restrições na posição de núcleo (Nukleus: Kern) em alemão: somente elementos com o traço [+soante] são permitidos nele, ou seja, vogais, glides e demais soantes (nasais e líquidas), enquanto as obstruintes e laringais podem permanecer somente na posição de onset ou de coda. Essa constatação valida, sobretudo, a divisão entre núcleo e coda. Para sequências no núcleo, valem as seguintes restrições de competição: após vogais na primeira posição do núcleo, somente os glides [j] e [w] são permitidos (como podemos observar nos ditongos [aj], [aw] e [oI]), além do r-vocalizado, transcrito foneticamente como [e [ ] . Em contrapartida, após vogais no núcleo, qualquer consoante pode ocorrer na posição de coda (RAMERS, 1998, p. 102).

A análise de Ramers (1998), entretanto, ao menos no tocante ao r-vocalizado, não nos parece apropriada, pois esse elemento pode aparecer depois de vogais longas, diferentemente dos glides (ver a discussão em Mücke (1997), a seguir). Se adotarmos a concepção de que o núcleo do alemão tolera até duas moras, o que a inexistência de glides seguindo vogais longas parece indicar, ao r-vocalizado apenas sobra a coda.

A seguir, ao se tratar da quantidade de posições esqueletais no núcleo da sílaba do alemão, como já apresentamos, somente dois elementos são permitidos, segundo Ramers (1998). As exceções, nesse caso, dizem respeito possivelmente às sequências [jaj] e [jaw], em vocábulos como jein (cruzamento vocabular de ' ja' e 'nein') e jaulen 'ganir', quando o primeiro segmento [j] tem valor de glide (no núcleo) e não como fricativa [j] (no ataque silábico).

Novamente, discordamos da posição de Ramers (1998), pois, na nossa visão, o glide à esquerda da vogal ocupa o lugar de onset. Para defender essa posição, temos pelos menos dois argumentos fonológicos: 1) o cruzamento de ja e nein resulta em jein, o que indica que o $j$ ocupa a mesma posição do $n$ em nein, ou seja, o onset; 2) se o onset não fosse ocupado em palavras como jaulen e jein, haveria a propensão 
para a oclusão glotal, fenômeno bastante recorrente em sílabas alemãs desprovidas de onset (acht 'oito', por exemplo), sobretudo as iniciais, mas que não ocorrem nesses contextos: *2jaulen, *2ja. Isso sugere que em jaulen e ja o onset já esteja ocupado.

A Fonologia CV (CV Phonology), desenvolvida por Clements e Keyser (1983), apresenta um tratamento que se distancia da visão de Kahn (1976), no sentido de que aqueles propõem uma camada intermediária que governaria os segmentos afiliados à sílaba. Nesse modelo, segundo Clements e Keyser (1983, p. 8), introduz-se "uma terceira camada na representação da sílaba que intermedeia a camada da sílaba e a camada segmental" "13 (tradução nossa), que os autores chamam de camada CV. Os elementos nessa camada diferenciam picos (núcleos) silábicos de elementos das margens: segmentos dominados por V são interpretados como núcleos silábicos; aqueles dominados por $\mathrm{C}$, como não nucleares (onsets e codas). Uma das consequências dessa análise é a possibilidade de descartar o traço $\left[ \pm\right.$ silábico], que, na análise linear de SPE,${ }^{14}$ era o responsável pela silabicidade (ou assilabicidade) dos segmentos, ou seja, pelo status desses de serem núcleo ([+silábico]) ou margens ([-silábico]) da sílaba.

Considerando isso, tendo como base a análise proposta por Mücke (1997), a posição dos glides na estrutura interna da sílaba do alemão padrão sugere discussão. Ainda segundo Mücke (1997, p. 80), admitindo-se a posição dos subconstituintes do núcleo silábico, resultam, dessa maneira, dois problemas a respeito dos glides no alemão:

- Primeiro problema: o núcleo tem, no máximo, duas posições: o alemão não tem tritongos. Assim, os glides não ocorrem antes de vogais no núcleo ou após ditongos ou vogais longas. Se há ou não glides precedentes de vogais, isto ainda não se sabe; a duração subjacente de algumas vogais deve ser, portanto, neutralizada antes da posição do glide-/r/ para que não se exceda a restrição da quantidade do núcleo. (MÜCKE, 1997)

\footnotetext{
13 "[we introduce] a third tier in syllable representation which mediates between the syllable tier and and the segmental tier [and which we call the CV-tier]."

${ }^{14}$ Sigla para The Sound Pattern of English, Chomsky e Halle (1968).
} 
- Segundo problema: o valor diverso dos glides pré- e pós-vocálicos na estrutura da sílaba. Posto que o glide pós-vocálico está associado ao subconstituinte obrigatório - o núcleo - então ele não pode ocupar mais a posição da borda da extremidade (a posição da coda silábica) e contará para o núcleo da sílaba. No entanto, não é claro, ainda, o motivo pelo qual um glide pré-vocálico deve pertencer ao onset da sílaba e, em contrapartida, o glide pós-vocálico à posição de núcleo. Isso representa um peso desigual dos segmentos de mesma sonoridade. $\mathrm{O}$ vocábulo <jein>, apresentado abaixo, na Figura 9, serve de exemplo.

FIGURA $9-<$ jein $>$

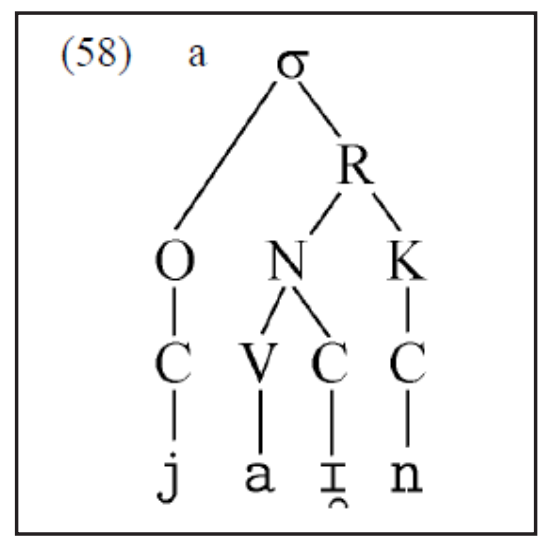

Fonte: Mücke, 1997, p. 81; Ilustração 58(a)).

Na representação desse cruzamento vocabular de $j a$ 'sim' + nein 'não', formando, portanto, o vocábulo "jein", podemos visualizar o glide /j/ em posição de onset (ataque silábico), precedendo a vogal /a/, em posição de núcleo da sílaba, juntamente com a vogal alta assilábica /I/. Consequentemente, devido ao fato de a sílaba, na estrutura fonológica do AP, permitir somente dois elementos na posição de núcleo, torna fonologicamente inaceitável introduzir o glide /j/ na posição pré-vocálica de núcleo silábico. Haveria, com isso, uma posição de núcleo vocálico composta, exclusivamente, de três elementos (CVC).

Essa assimetria, exposta por Mücke como o primeiro problema para a posição dos glides, não nos parece algo de difícil solução. Considerando que o AP seja uma língua que requer onset em sua 
estrutura silábica, qualquer glide à esquerda estará mais propenso ao onset. Comportamento distinto terá o glide à direita, pelo que teremos uma segunda mora associada ao núcleo silábico, algo suportado pela estrutura silábica do AP.

Na Figura 10, abaixo, podemos verificar o vocábulo 'Fjord', na estrutura hierárquica da sílaba do alemão. Nela, observamos que o glide /j/ aparece na posição de ataque silábico após a fricativa labiodental surda /f/. Já na posição de núcleo silábico, há a vogal posterior / /, seguida da vogal central baixa/e/ (r-vocalizado), em posição pós-vocálica de núcleo silábico. Por fim, ocorre a realização da consoante plosiva /t/em posição da coda simples, como se pode observar:

FIGURA $10-<$ Fjord $>$

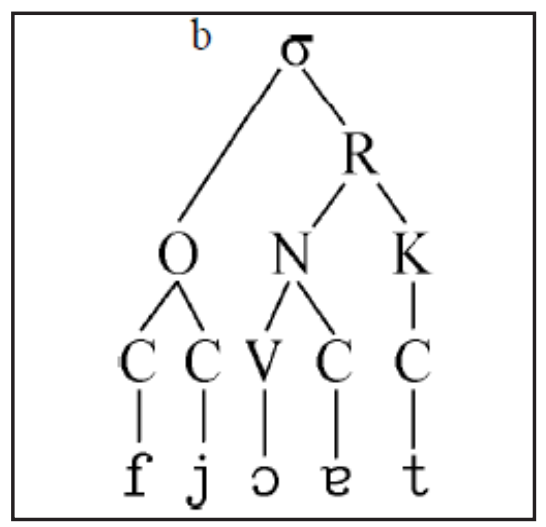

Fonte: Mücke, 1997, p. 81; Ilustração 58(b)).

Segundo Mücke (1997), a vogal central baixa / e/ está na segunda posição (C) de um núcleo complexo, como podemos visualizar acima. A análise alternativa seria inseri-lo na posição de coda complexa, precedendo, assim, a consoante plosiva/t/. Argumentos para uma ou outra análise estão fora do escopo deste trabalho. Teríamos, por conseguinte, outra representação silábica hierárquica para o mesmo vocábulo, que também não feriria a escala de sonoridade. Já em relação à "abertura da sílaba", por assim dizer, baseando-se em Neef (1996, p. 66 apud MÜCKE, 1997, p. 86), somente o elemento mais sonoro pode iniciar a posição de núcleo da sílaba em alemão (consequentemente, isso faz os glides pré-vocálicos serem "movidos" para a posição de ataque silábico). 
Essa característica é, para nós, resultado da obrigatoriedade de onset no AP. Wiese (1996, p. 236 apud Ib., p. 81), por sua vez, afirma e reforça, também, o seguinte: “[...] todos os on-glides são consoantes, assim como obstruintes e algumas soantes, ao passo que os off-glides são vogais." 15 Além desse exemplo, exibido na Figura 10, retirado de Mücke (1997), traremos à discussão vocábulos como Spanien 'Espanha', Italien 'Itália', Brasilien 'Brasil', Linie 'linha'. Esses vocábulos apresentam certa peculiaridade, pois têm a vogal alta/I/, antecedendo uma vogal não alta. As divisões silábicas propostas pelo Dicionário Duden $(2015)^{16}$ online, para 'Spanien' e 'Italien', por exemplo, são 'Spa.ni.en'17 e 'Ita.li.en', ${ }^{18}$ embora a mesma fonte forneça as seguintes transcrições: ['Spa:nı̊n] e [i'talı̊n], respectivamente.

Apesar de a separação vocabular apresentada pelo Duden sugerir a existência de três sílabas nessa palavra (['Spa:.nI.ən]), de acordo com a transcrição fonética apresentada pelo mesmo dicionário, existem apenas duas sílabas em 'Spanien': ['Spa:] e [nı̃ən], fato indicado pela assilabicidade da vogal alta. ${ }^{19}$ Nessa transcrição, podemos observar que a vogal alta é interpretada como vogal assilábica e, por estar precedendo o Schwa [ə], só pode estar na posição pré-vocálica de núcleo silábico (do contrário, ela não poderia ser vogal assilábica). Parece-nos que temos um paradoxo aqui: como uma vogal transcrita assilabicamente pode constituir núcleo silábico?

Nossa proposta seria a possível transcrição fonética ['Spa:njən] com apenas duas sílabas, isto é: ['Spa:] e [njən], na qual o glide [j] ocorre na posição de segundo elemento de um onset complexo. Essas transcrições podem parecer não muito diferentes entre si em suas realizações fonéticas, mas sugerem relações distintas entre os constituintes silábicos. Em outras palavras, não seriam meramente variantes notacionais, mas indicariam como o AP se estrutura silabicamente.

\footnotetext{
${ }^{15}$ Wiese (1996, p. 236 apud MÜCKE, 1997, p. 81): "In other words, all on-glides are consonants, some obstruents and some sonorants, while all off-glides are vowels." ${ }^{16} \mathrm{http}: / /$ www.duden.de

${ }^{17} \mathrm{http}: / /$ www.duden.de/rechtschreibung/Spanien

${ }^{18} \mathrm{http}: / /$ www.duden.de/rechtschreibung/Italien

19 É provável que haja variação em termos de assilabicidade da vogal alta e, consequentemente, no número de sílabas, mas não trataremos dessa variação aqui.
} 
O mesmo podemos dizer dos vocábulos Brasilien, Linie etc., estando o glide na fronteira da segunda para a terceira sílaba. E, por fim, como Mücke (1997, p. 74) reforça: "Os glides não são, somente foneticamente, vogais breves e assilábicas. Eles podem, também fonologicamente, ser derivados, com base no modelo derivacional, das suas respectivas vogais altas, como exemplificado, a seguir, em Wiese (1996) e Hall (1992)": ${ }^{20}$

(1) $[\mathrm{j}]$ respectivamente $[\mathrm{I}]$ como variante do /I/
$/ \mathrm{aI} / \rightarrow[\mathrm{aI}]$ respectivamente $/ \mathrm{aI} / \rightarrow[\mathrm{aj}]$

Verificamos, por conseguinte, pela representação acima, que a mesma vogal assilábica [I] parece ser intercambiável com o glide [j]. Isso nos permite afirmar que, na estrutura fonológica subjacente, não haveria o glide, mas a vogal alta [I] breve.

Essa solução é muito mais corriqueira, se pensarmos na situação do glide fonético à direita da vogal. Entretanto, mais algumas considerações devem ser feitas acerca da vogal alta/glide à esquerda, para sondarmos a possibilidade de eliminarmos o glide da subjacência. É isso que veremos na próxima Seção.

\section{O glide na sílaba do alemão: uma análise pela TO}

De maneira geral, diz-se que o glide faz parte do sistema fonológico do alemão (RAMERS, 2007). A pergunta que se coloca é se haveria necessidade de postular subjacentemente esse elemento como um glide/ aproximante ou se é uma vogal com saída fonética de glide.

Investigamos, nesta Seção, se é possível dar conta, em uma análise otimalista, da diferença em alemão entre um input vocálico e um output glide e sua posição na sílaba, ou seja, como resultado de um ranqueamento de restrições. Diferentemente de modelos predecessores, a

${ }^{20}$ Em alemão: "Nicht nur phonetisch sind 'Glides' kurze, nichtsilbische Vokale. Sie können auch phonologisch im Rahmen von derivationellen Theorien von den entsprechenden hohen Vokalen abgeleitet werden, wie beispielweise bei WIESE (1996) und HALL (1992).” (MÜCKE, 1997, p. 74):

(44) [j] bzw. [I] als Variante von /I/ $/$ aI $/ \rightarrow$ [aI] bzw. /ai/ $\rightarrow$ [aj] 
TO prevê um modelo de gramática, na qual operam restrições universais, cuja importância - expressa pela hierarquia - é particular de línguas individuais. A TO não faz asserções específicas sobre os formatos da sílaba, por exemplo, utilizando-se, nesse particular, dos achados e discussões encontradas em outras teorias. Em relação a essas teorias, costuma diferir basicamente pelo fato de que regras e princípios, como tais, são abandonados em razão de restrições.

Retomando algumas discussões realizadas anteriormente, podemos investigar primeiramente se é possível considerar que o glide pré-nuclear seja subjacentemente uma vogal. Assim:

\section{(2) $/ \mathrm{ia} / \rightarrow[\mathrm{ja}]^{21}$}

Antes de prosseguirmos com essa discussão, vale ressaltar que, conforme já dissemos, consideramos que o glide pré-nuclear, como em ja 'sim', está na posição de onset, não se tratando de um elemento nuclear. Para essa assunção, arrolamos dois argumentos. O primeiro é que, no AP, em sílabas como a única de $a c h t$ 'oito', desprovidas de onset, ocorre a epêntese glotal [?axt]; o mesmo não ocorre com palavras como jacht 'iate', que é realizada como [jaxt], não *[? Iraxt]). Sendo assim, podemos dizer que há, no AP, uma restrição alta que proíbe realizações sem onset. Outro argumento vem do cruzamento vocabular de ja 'sim' + nein 'não' = jein. O resultado desse cruzamento é a realocação de [j] no lugar de [n], este último indiscutivelmente onset. Se o [j] fizesse parte do núcleo, o cruzamento deveria ser *njein [njånn] (ou *[nıraın]), o que não ocorre. Acrescentamos também que nossas representações nos tableaux utilizados nessa Seção demonstram a silabação (.), mas a constituição da sílaba indica se o glide está no onset ou no núcleo (formando ditongo crescente), assim:

\footnotetext{
${ }^{21}$ Em nossa representação, o glide [j] é um elemento de função consonantal, figurando na borda da sílaba, ao passo que o símbolo [I] representa uma vogal alta pré- ou pósnuclear, em um núcleo dominado por uma vogal de maior sonoridade. Vale lembrar que o mapeamento de uma vogal alta anterior e um desses elementos não configuram violação de fidelidade, uma vez que suas configurações apenas se referem à sua posição na sílaba, não à qualidade do segmento em si.
} 
(3) Representações silábicas de Jacht:

a)

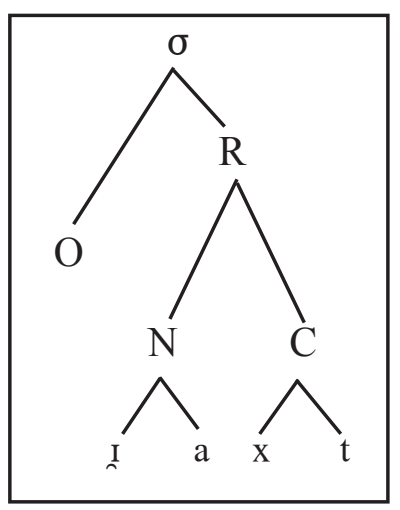

b)

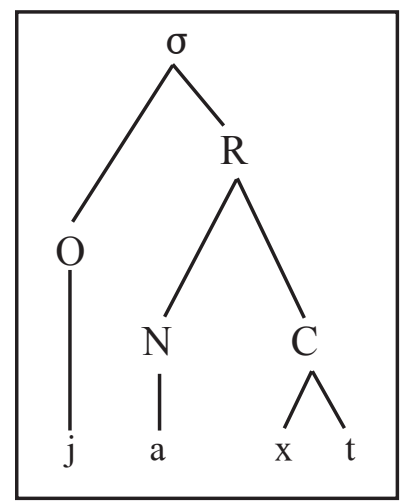

A seguir, fazemos uma análise otimalista sobre a formação do glide e sua posição na estrutura do AP, a partir de uma vogal alta subjacentemente, testando a viabilidade dessa hipótese, em uma abordagem baseada em restrições. Como em ja o glide está na posição de onset, podemos pensar nas seguintes restrições que atuariam nessa conformação silábica:

(4) OnSET: assinale violação a cada sílaba desprovida de onset (PRINCE; SMOLENSKY, 1993).

(5) SonFAll: dada uma sequência tautossilábica, bimoraica de segmentos, atribua uma marca de violação caso a sonoridade do segmento mais à direita seja maior do que a do segmento mais à esquerda. (cf. ROSENTHALL, 1994; CARVALHO, 2014).

(6) CompleX ${ }^{\text {Onset: }}$ assinale uma violação a onsets com mais de um segmento (KAGER, 1999).

(7) DEP-IO: todo segmento no output tem um correspondente no input; proibida a epêntese (McCARTHY; PRINCE, 1995).

(8) IDENT [voc]: assinale marca de violação caso haja discrepância referente ao valor do traço [vocálico] (seguindo McCarthy (2008)). 
Nesse caso, seguindo Padget (2008), estamos considerando que há distinção entre $[\mathrm{i}, \mathrm{u}]$ e $[\mathrm{j}, \mathrm{w}]$ no que se refere ao traço [vocálico], ${ }^{22}$ sendo os dois primeiros valorados positivamente quanto a esse traço, e os últimos, negativamente. Isso significa que a restrição IDENT [voc] é dominada no AP, conforme veremos adiante.

A seguir, vemos um tableau $\operatorname{combinados}^{23}$ para o input /iaxt/ 'iate', que apresenta status de vogal (ou seja, [+vocoide]) para o segmento em análise aqui; na sequência, vemos um tableau combinado para / fiord/ 'fiorde'.

(9) Tableau combinado para /iaxt/ Jacht 'iate'

\begin{tabular}{|c|c|c|c|c|c|}
\hline /iaxt/ & ONSET & SonFALL & DEP-IO & $*$ COMP $^{\text {ONSET }}$ & IDENT(Voc) \\
\hline$\rightarrow$ jaxt & & & & & $*$ \\
\hline a. i.axt & $* * \mathrm{~W}$ & & & & $\mathrm{~L}$ \\
\hline b. $\operatorname{Iaxt}$ & $* \mathrm{~W}$ & $* \mathrm{~W}$ & & & $*$ \\
\hline c. PIaxt & & $* \mathrm{~W}$ & $* \mathrm{~W}$ & & $*$ \\
\hline
\end{tabular}

(10) Tableau combinado para /fiord/ Fjord 'fiorde'

\begin{tabular}{|l|c|c|c|c|c|}
\hline fiord & ONSET & SONFALL & DeP-IO & ${ }^{*}$ ComP ONser & IDENT[Voc] \\
\hline$\rightarrow$ fjort ${ }^{24}$ & & & & $*$ & $*$ \\
\hline a. fi.ort & $* \mathrm{~W}$ & & & $\mathrm{~L}$ & \\
\hline b. firort & & ${ }^{*} \mathrm{~W}$ & & $\mathrm{~L}$ & $* \mathrm{~L}$ \\
\hline c. fi.?ort & & & $* \mathrm{~W}$ & $\mathrm{~L}$ & $*$ \\
\hline
\end{tabular}

${ }^{22}$ Como lembra Padgett (2008), essa restrição conflita com a restrição *P/j, que proíbe que glides sejam núcleos de sílaba, havendo mesmo a necessidade de postular a dominância $* \mathrm{P} / \mathrm{j}>>$ Ident (voc) como universal.

${ }^{23}$ O tableau combinado (McCARTHY, 2008) é uma junção do tableau avaliativo tradicional e o comparativo (PRINCE, 2002); este nos indica argumentos para o ranqueamento de restrições. $\mathrm{O} \mathrm{W}$ no tableau indica que a restrição favorece, comparativamente ao candidato na mesma linha, o candidato selecionado (ou Winner, 'ganhador'); o L indica que aquela restrição favorece o perdedor (ou Loser). De modo geral, um $\mathrm{W}$ à esquerda de L indica a dominância entre as restrições nas respectivas colunas.

${ }^{24}$ Não é parte da discussão nesse texto, mas o desvozeamento final de obstruentes em línguas como o alemão (e holandês, russo, polonês, entre outras) pode ser analisado, em uma abordagem otimalista, como decorrente da relação de dominância *VoicedCoda $>>$ Ident-IO (voz). Ver Kager (1999, p.40-41). 
A restrição DEP-IO milita contra a epêntese. Sabemos que a epêntese (da oclusiva glotal) pode ocorrer no AP para providenciar onset em sílabas desprovidas desse elemento, fato demonstrado, por exemplo, pelo mapeamento /axt/ $\rightarrow$ [?axt] 'oito'. Por conta disso, temos como dada a relação de dominância OnSET $>$ DEP-IO (ALBER, 2001). A restrição SonFall evita ditongos crescentes, o que está de acordo com a inexistência de epêntese glotal em palavras como ja e Jacht. O candidato $a$ comete duas violações de ONSET. Note-se que essa formação seria a preferida por falantes de Português Brasileiro, por exemplo (como é o caso da adaptação de yatch (ing.), em boa parte dos dialetos do PB: [i.a.t $\mathrm{I}]$ ). Um item como $b$ em (9) violaria não apenas SonFALL, como também OnSET. Note-se também que o hiato é a forma preferida para a adaptação do item fjord (norueguês) no PB: [fi.o]rde. Pelo que podemos ver aqui, é possível dar conta da posição do glide pré-nuclear na estrutura silábica do alemão, considerando que ele seja subjacentemente uma vogal alta /i/ em casos como em Jacht e Fjord, resultando na superfície glides em onset. Como dito anteriormente, uma das principais evidências para essa assunção é a inserção de epêntese glotal para sílabas desprovidas de onset.

No tableau (9), podemos ver as relações de dominância ONSET, SonFall $>$ Ident(voc). Já no tableau (10), vemos que Dep-IO, Onset e SONFALl devem dominar *COMP ${ }^{\text {ONSET }}$. Não há motivos para hierarquizar Onset e SonFall, o que nos leva a crer que devam estar no mesmo patamar hierárquico.

Para mostrar que a ortografia pode ser um complicador nesses casos, vamos analisar itens grafados na ortografia oficial com a vogal alta, como os já citados anteriormente Italien, Spanien e Brasilien.

(11) Tableau combinado para Spanien 'Espanha'

\begin{tabular}{|c|c|c|c|c|c|}
\hline /Spanion/ & Ons & SONFALL & Dep-IO & ${ }^{*}$ COMP $^{\text {ONSET }}$ & IDENT(voc) \\
\hline$\rightarrow$ Spa.[njən] & & & & $*$ & $*$ \\
\hline a. Spa.[ni.ən] & $* \mathrm{~W}$ & & & $\mathrm{~L}$ & \\
\hline b. Spa.[nIən] & & $* \mathrm{~W}$ & & $\mathrm{~L}$ & * \\
\hline c. Spa.[ni.Rən] & & & $* \mathrm{~W}$ & & \\
\hline
\end{tabular}


Em (11), nota-se, a partir de Ws à esquerda de Ls, que as restrições Onset e SonFall devem dominar ${ }^{*}$ Comp ${ }^{\text {Onset }}$. Em outras palavras, é melhor incorrer em violação da complexidade em onset que ter um ditongo crescente ou ter um hiato. De fato, o alemão é uma língua bastante permissiva quanto à formação de clusters, quer em onset, mais fortemente, quer em coda.

Sendo assim, é possível detectar convergência nos tipos abordados e oferecer tratamento unificado de uma vogal alta subjacente ser realizada foneticamente como glide, avaliada como estando na posição de onset - simples ou complexo. Para isso, é necessário admitir que a hierarquia de restrições seria Onset, SonFall $>>$ DEP-IO $>$ * COMPlex ${ }^{\text {ONSET }}$, IDENT(voc). Em outras palavras, o mapeamento de $/ \mathrm{i} / \rightarrow$ [j] é tolerado no AP para uma vogal alta que anteceda outra de maior sonoridade, uma vez que essa língua requer onset (e tolerando-o complexo), como forma de evitar a epêntese, e proíbe o ditongo crescente.

Ressalte-se que, como dito, consideramos que a ausência de epêntese de glotal em itens como Jacht seja evidência de que a o glide esteja em onset. Embora não seja tão evidente se em itens como Spanien o glide seja parte de um onset complexo ou forme um elemento prévocálico dentro do núcleo, a nossa assunção de que seja a primeira situação decorre do fato de que o alemão é uma língua muito permissiva ao onset complexo. Essa assunção também dá um tratamento unificado à formação do glide e sua posição na sílaba do AP. Experimentos e o comportamento em jogos linguísticos poderiam indicar se as previsões dessa assunção estão corretas.

Com relação às vogais altas /i/ e /u/ pós-nucleares, a restrição SonFall não as proíbe como participantes do núcleo, o que permite a existência de ditongos decrescentes no AP. Por fim, colocamos um tableau avaliativo, mostrando a hierarquia.

(12) Tableau avaliativo para /iaxt/ Jacht 'iate'

\begin{tabular}{|c|c|c|c|c|c|}
\hline /iaxt/ & ONSET & SONFALL & DEP-IO & $* \mathrm{COMP}^{\mathrm{ONSET}}$ & IDENT[VOc] \\
\hline$\rightarrow$ a. jaxt & & & & & $*$ \\
\hline b. i.axt & $* ! *$ & & & & \\
\hline c. Iaxt & $* !$ & $* !$ & & & \\
\hline d. PIaxt & & $* !$ & $*$ & & \\
\hline
\end{tabular}


(13) Tableau avaliativo para /fiord/ Fjord 'fiorde'

\begin{tabular}{|l|c|c|c|c|c|}
\hline fiord & ONSET & SONFALL & DEP-IO & $*$ COMPONSET & IDENT[Voc] \\
\hline$\rightarrow$ a. fjort & & & & $*$ & $*$ \\
\hline b. fi.ort & $* !$ & & & & \\
\hline c. fiort & & $* !$ & & & \\
\hline d. fi.port & & & $* !$ & & \\
\hline
\end{tabular}

No tableau avaliativo (12), para Jacht, podemos ver que o candidato $a$ é o único que respeita as duas restrições mais altas da hierarquia, ONSET e SonFALl, apesar de violar a restrição que milita contra a discrepância entre input e output, no que se refere ao traço [ \pm vocálico]. Ainda nesse tableau, SonFall parece não desempenhar papel relevante, uma vez que o candidato $d$ já estaria barrado por DeP-IO e $c$, por Onset. Quanto ao item Fjord, no tableau (13), não há fortes evidências para a opção entre [fjo]rd e [fI.. ] $r d$ (essa barrada exclusivamente por SonFALL), que vão além de uma abordagem unificada entre itens como Jacht e Fjord e a grande tolerância do AP à complexidade em onset. Em um diagrama de Hasse, teríamos:

(14) Hierarquia (em diagramas de Hasse)

Diagrama de Hasse (I)

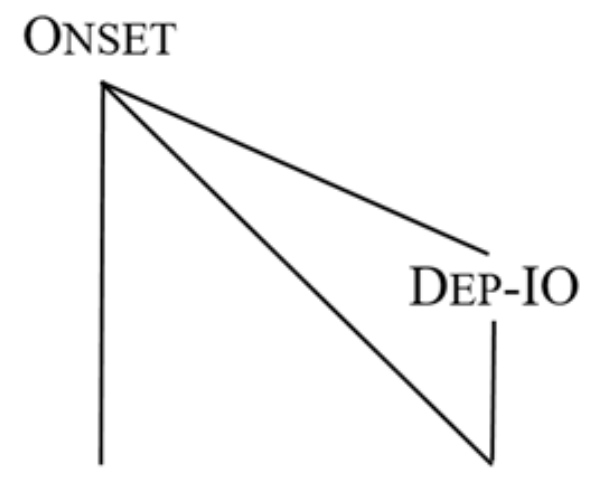

IDENT[Voc]

*COMPONSET 
Diagrama de Hasse (II)

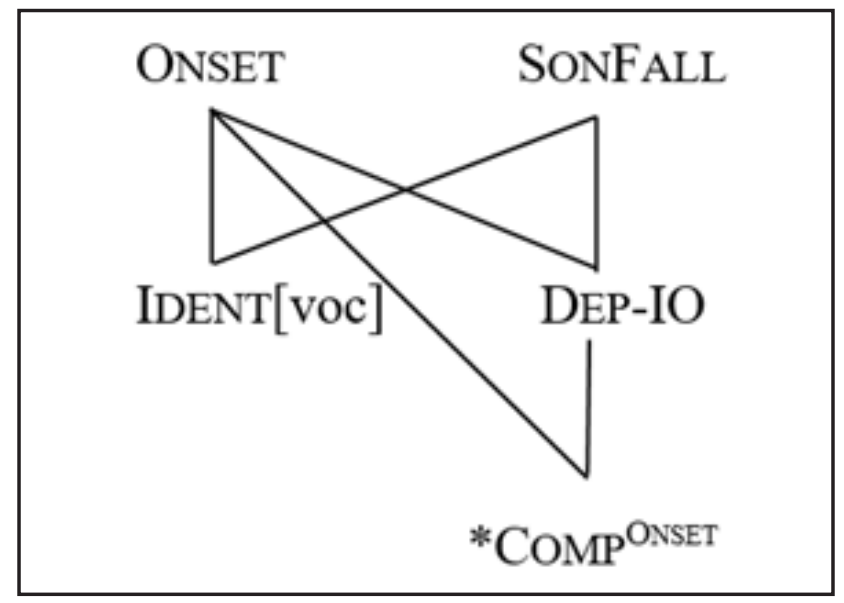

Nos diagramas de Hasse apresentados acima, vemos duas possibilidades. No primeiro diagrama, vemos a hierarquia sem SonFALL. Essa hierarquia dá conta do fato de que o glide se realize no onset em itens como Jacht 'iate' e ja 'sim'. Em outras palavras, SonFALl não desempenha papel importante para esse caso. No caso de itens como Fjord 'fiorde', temos a possibilidade de interpretar o glide como: (a) elemento pré-nuclear ou (b) integrante do onset complexo. Caso SonFAll seja admitida na hierarquia na posição que indicamos aqui, o glide será avaliado como (b); caso contrário, seria possível ser avaliado como (a). Defendemos que SonFall integra esse ponto da hierarquia, sobretudo porque (1) essa análise assegura a alta tolerância do AP ao onset complexo; além disso, (2) haveria uma abordagem unificada para itens como Jacht e Fjord.

\section{Considerações finais}

Defendemos, neste artigo, a retirada do status do glide anterior na representação subjacente do alemão. No lugar desse segmento, haveria apenas a vogal alta equivalente. A ocorrência de glides na superfície deve ser atribuída à hierarquia, resolução de conflitos entre restrições violáveis, como prevista em uma análise otimalista. A formação do glide e a consequente posição dessa vogal alta na sílaba também é determinada por essa hierarquia. 
Em relação aos problemas citados por Mücke (1997), reproduzidos anteriormente, podemos dizer que, em relação ao primeiro problema, glides pré-vocálicos são pertencentes ao onset, não ao núcleo, o que exclui a possibilidade de existência dos assim chamados tritongos no AP. Glides pós-vocálicos fazem parte do núcleo, a menos que este já tenha dois elementos, como podemos ver pelo fato de vogais longas serem evitadas antes de glides.

Em relação ao segundo, a assimetria em relação à posição dos glides pré- e pós-vocálicos - o primeiro fazendo parte do onset e o segundo, do núcleo - decorre da alta posição na hierarquia da restrição que requer onset no $\mathrm{AP}$ e à proibição de dois elementos no núcleo, sempre que a sonoridade do primeiro elemento for menor que o seguinte. No que se refere à marcação de constituintes silábicos, essa assimetria pode ser decorrente da assimetria existente entre esses constituintes: o onset (exigido em muitas línguas; proibido por nenhuma) e a coda (proibido em muitas línguas).

Também defendemos aqui que o glide à esquerda da vogal ocupa o lugar de onset. Para justificar essa posição, trouxemos à baila duas evidências fonológicas: 1) o cruzamento de $j a$ 'sim' e nein 'não' resulta em jein (cruzamento vocabular de 'sim' e 'não'), o que indica que o $j$ ocupa a mesma posição do $n$ em nein, ou seja, o onset (*njein); 2) se o onset não fosse ocupado em palavras como Jacht, jaulen e jein, haveria a propensão para a oclusão glotal, fenômeno bastante recorrente em sílabas alemãs desprovidas de onset (como em acht 'oito' [?axt]), sobretudo as iniciais, mas que não ocorrem nesses contextos: *? jaulen, $* ?$ ja. Isso sugere que em jaulen e $j a$ o onset já esteja ocupado. Esse fato pode ser atribuído à alta posição, em AP, da restrição ONSET. A grande tolerância à complexidade em onset no alemão nos leva a postular que a restrição CoMP ONser seja dominada por SonFall. O AP tolera epêntese para o preenchimento do onset (ONSET > DEP-IO), mas não se houver a possibilidade de ser providenciado onset a partir de segmento subjacente, mesmo que o onset se torne complexo; por esse motivo Dep-IO $>>$ Comp ${ }^{\text {NSET }}$.

Considerando que a distinção entre [j] e [i] (e entre [w] e [u]) pode ser o traço [vocálico], seguindo Padgett (2008), em línguas como o alemão apenas emergem segmentos com o traço [-vocálico] (glides), por conta de a restrição IDENT(voc) ser dominada por ONSET e por SONFALL. Defendemos que SonFall atue no AP, sobretudo porque (1) há forte tolerância do AP ao onset complexo e porque, com isso, (2) atinge-se uma abordagem unificada para itens como Jacht e Fjord. 


\section{Agradecimentos}

Agradecemos às sugestões enriquecedoras dos pareceristas anônimos. Os erros residuais são de nossa responsabilidade.

\section{Referências}

ALBER, Birgit. Regional variation at edges: glottal stop epenthesis and dissimilation in Standard and Southern varieties of German, 2001. Disponível em: <http://roa.rutgers.edu/files/417-0900/roa-417-alber-1. pdf $>$.

BLEVINS, Juliette. Syllable in phonological theory. In: GOLDMISTH, John (Ed.). The Handbook of Phonological Theory. Cambridge: Blackwell Publishers, 1995. p. 206-244.

BRENNER, Koloman; HUSZKA, Balázs; WERK-MARINKÁS, Csaba. Deutsche Phonetik: Eine Einführung. Budapest - Veszprém: Bölcsész, Konzorcium, 2006.

BROCKHAUS, Wiebke. The syllable in German: Exploring an alternative. In: HULST, Harry van der et al. The syllable: Studies in Generative Grammar 45. Berlin, New York: Mouton de Gruyter, 1999. p. 169-218.

CARVALHO, Fernando O. de. Disparidades entre Input e Output em sequências vocálicas: equilibrando contraste e marcação nas gramáticas das línguas naturais. 2014. Tese (Doutorado) - Universidade Federal do Rio de Janeiro, 2014.

CLARK, J.; YALLOP, Colin. An Introduction to Phonetics and Phonology. 2. ed. Cambridge (USA): Blackwell, 1995.

CLEMENTS, George Nick. The role of the sonority cycle in core syllabification. In: KINGSTON, J.; BECKMAN, M. (Ed.). Papers in Laboratory Phonology I: between the Grammar and Physics of Speech. Cambridge: Cambridge University Press, 1990. p. 283-333. Doi: https:// doi.org/10.1017/CBO9780511627736

CLEMENTS, George Nick; HUME, Elisabeth V. The Internal Organization of Speech Sounds. In: Goldsmith, J. A. (Ed.). The Handbook of Phonological Theory. Oxford: Blackwell Publishers, 1995. p. 245-306. 
CLEMENTS, George N.; KEYSER, Samuel J. CV Phonology: a generative theory of the Syllable. Cambridge: The MIT Press, 1983.

COLLISCHON, Gisela. O acento em português. In: BISOL, Leda (Org.). Introdução a estudos de fonologia do português brasileiro. 3. ed. Porto Alegre: EDIPUCRS, 2001.

CRISTÓFARO SILVA, Thais. Dicionário de Fonética e Fonologia. São Paulo: Contexto, 2011.

DAMULAKIS, Gean Nunes. Dicas de pronúncia do alemão: fonética e fonologia. Projekt: Revista Brasileira dos Professores de Alemão, Abrapa, n. 46, p. 61-65, abr. 2008. Disponível em: < http://www.abrapa.org.br/pdf/ Projekt2008.pdf>. Acesso em: 8 dez. 2015.

DELATTRE, Pierre. Comparing the vocalic features of English, German, Spanish and French. IRAL/Julius Gross, Heidelberg, v. II, n. 2, p. 70-97, jul. 1964.

D. KENT, Ray. READ, Charles. Análise acústica da fala. São Paulo: Cortez, 2015.

JESPERSEN, O. Lehrbuch der Phonetik. Leipzig und Berlin, 1904.

KAGER, René. Optimality Theory. Edinburgh: Cambridge University Press, 1999.

McCARTHY, John. Doing Optimality Theory. Malden: Blackwell Publishing, 2008.

McCARTHY, John; PRINCE, Alan. Faithfulness and Reduplicative Identity. In: BECKMAN, Jill; DICKEY, Laura W.; URBANCZYK, Suzanne (Ed.). University of Massachussets Occasional Papers in Linguistics 18. Amherst, MA: GLSA Publications, 1995. Disponível em Rutgers Optimality Archive, ROA-103.

KAHN, Daniel. Syllable-based Generalizations in English Phonology. 1976. Dissertation (Ph.D.) - MIT, 1976.

MADDIESON, Ian. Syllable Structure. Disponível em: <http://wals.info/ chapter/12>. Acesso em: 9 abr. 2017.

MATEUS, Maria Helena; D’ANDRADE, Ernesto. The Phonology of Portuguese. New York: Oxford University Press, 2000. Cap. 3. 
MEIBAUER, Jörg et alli. Einführung in die germanistische Linguistik. J. B. Metzler: Berlin, 2007.

MÜCKE, Doris. 'Glides'im Deutschen - eine phonetisch-phonologische Untersuchung. 1997. 108 f. Dissertação (Mestrado em Linguística) - UniKöln, Köln, 1997.

O'GRADY, William; DOBROVOLSKI, Michael; KATAMBA, Francis. Phonetics: The sounds of language. In: STEPHEN, Adewole. Contemporary Linguistics: an Introduction. London; New York: Longman, 1990. p. 1-740. [Issues in Applied Linguistics, 1(1)].

PADGETT, J. Glides, vowels and features. Lingua, Elsevier, v. 188, p. 1935-1955, 2008. Doi: https://doi.org/10.1016/j.lingua.2007.10.002.

PRINCE, Alan. Arguing Optimality. In: COETZEE, Andries; CARPENTER, Angela; LACY, Paul de (Ed.). Papers in Optimality Theory II. Amherst: GLSA, UMass, 2002.

RAMERS, Karl-Heinz. Einführung in die Phonologie. München: Fink, 1998.

ROSENTHALL, Samuel. Vowel/Glide Alternation in a Theory of Constraint Interaction. 1994. Dissertation (Doctoral) - University of Massachusetts, Amherst, 1994.

SAUSSURE, Ferdinand de. Curso de Linguística Geral. São Paulo: Cultrix, 2006.

SAUSSURE, Ferdinand de. Escritos de Linguística Geral. São Paulo: Cultrix, 2002. 14d [Notas de fonologia; abertura; teoria da sílaba (1897?)].

SEARA, Izabel Christine; NUNES, Vanessa Gonzaga; LAZZAROTTOVOLCÃO, Cristiane. Fonética e fonologia do português brasileiro: $2^{\circ}$ período. Florianópolis: LLV/CCE/UFSC, 2011.

SELKIRK, Elisabeth O. The syllable. Dordrecht: Foris, 1982. v. 2, p. 337-385.

SIEVERS, E. Grundzüge der Phonetik: Breitkopf und Hartel, Leipzig, 1881.

SNOWLING, J. Margaret; HULME, Charles. The Science of Reading: a Handbook. Malden, Oxford, Carlton: Blackwell, 2005. 